\title{
An Investigation into the Effects of Various Process Conditions on the Tribological Performance of Pack Carburized Titanium with Limited Oxygen Diffusion
}

R. Bailey,

Email Richard.bailey@dmu.ac.uk

Y. Sun,

${ }^{1}$ Faculty of Technology, School of Engineering and Sustainable Development, De Montfort University, Leicester, LE1 9BH UK

Received: 17 November 2017

\section{Abstract}

In the present study, a new pack carburization technique for titanium has been investigated. The aim of this treatment is to produce a titanium carbide/oxycarbide layer atop of an extended oxygen diffusion zone $[\alpha-\operatorname{Ti}(\mathrm{O})]$. The effects of treatment temperature and pack composition have been investigated in order to determine the optimal conditions required to grant the best tribological response. The resulting structural features were investigated with particular interest in the carbon and oxygen concentrations across the samples cross section. The optimization showed that a temperature of $925{ }^{\circ} \mathrm{C}$ with a pack composition of 1 part carbon to 1 part energizer produced surface capable of withstanding a contact pressure of $\approx 1.5 \mathrm{GPa}$ for $1 \mathrm{~h}$. The process resulted in TiC surface structure which offers enhanced hardness $(2100 \mathrm{HV})$ and generates a low friction coefficient $(\mu \approx 0.2)$ when in dry sliding contact with an alumina $\left(\mathrm{Al}_{2} \mathrm{O}_{3}\right)$ ball. 
The process also produced an extended oxygen diffusion zone that helps to improve the load bearing capacity of the substrate.

\section{Keywords}

carburization
oxidation
titanium
tribology
wear

\section{Introduction}

Titanium has an excellent strength to weight ratio and a very high resistance to corrosion. Thus, titanium has found increasing industrial use in the aerospace, chemical processing, medical and power generation industries (Ref 1-3). The uses of titanium have been restricted to mostly non-tribological applications, due to the severe galling problem encountered during sliding contact, ultimately leading to high friction and wear ( $\operatorname{Ref} 4,5)$. The reason for titanium's poor tribological response has been well documented by Dong and Bell (Ref 5).

To improve the tribological response of titanium and its alloys, numerous surface modifications techniques have been developed, these include: Boronizing (Ref 6, 7), Nitriding (Ref 8, 9), thermal oxidation (Ref 4, 10-13) and carburizing (Ref 14, 15). Recently, the formation of hard and wear resistant layers on titanium and its alloys, using more economical methods such as laser alloying with carbon or boron (Ref 16), plasma boriding (Ref 17) and electrochemical boriding (Ref 18) have been investigated. Surface engineering allows for the modification of the plasticity index on the titanium surface. By modifying the hardness and Young's modulus at the materials surface, the plasticity index can be decreased to promote elastic contact. Reducing the plasticity index changes the mode of surface contact. The sole purpose of these techniques is to generate surfaces that are no longer susceptible to galling and seizure, while maintaining the bulk characteristic of the material. However, for high stress applications, 
such as those found in gears and bearings, deep case hardening is required. None of the above methods are able to successfully achieve this level of protection (Ref 19).

Recently, a new pack carburization technique for titanium was demonstrated (Ref 20). The process was novel as it produced a titanium carbide/oxycarbide layer atop of an extended oxygen diffusion zone $[\alpha-T i(O)]$. Initial tribological tests demonstrated that the pack carburized titanium with oxygen diffusion (PCOD) significantly enhanced the dry tribological properties of titanium, in terms of much reduced friction, improved wear resistance and enhanced load bearing capacity. When the PCOD treatment is directly compared to the other surface modification techniques available for titanium, it was shown to produce a significantly harder surface [2100 HV (Ref 20)] than that produced by gas nitriding [1800 HV (Ref 9)] and thermal oxidation [1035 HV (Ref 11)]. One of the most significant benefits of this process is the extended diffusion zone produced and its ability to with stand high contact loads. This traditional load bearing capacity is something traditional titanium carburization cannot achieve, due to the low solubility of carbon in titanium. When PCOD is compared directly with thermally oxidized titanium, observed wear rates that are two orders of magnitude lower ( $\operatorname{Ref} 20)$. This same study also compared the frictional response of the PCOD titanium against that of AISI 440C, again a much reduced wear rate and friction level was observed.

In this study, the optimization of the PCOD surface treatment technique will now be presented in terms of overall war rate. Experiments were conducted to investigate the optimal carburizing conditions required to improve the tribological properties of CP-titanium. The effect of both the temperature and pack composition is presented to show the optimal condition for the best tribological performance.

\section{Experimental}

Commercially pure titanium (CP-Ti; grade 2, 99.4\% purity) was used as the substrate material. Samples of $20 \mathrm{~mm} \times 20 \mathrm{~mm} \times 2 \mathrm{~mm}$ were prepared by cutting an as-received CP-Ti plate. The samples were then manually ground using progressively finer $\mathrm{SiC}$ grinding papers down to 
the P1200 grade, resulting in a surface finish of $0.20 \mu \mathrm{m}(R a)$. The samples were then ultrasonically cleaned for $15 \mathrm{~min}$ in methanol.

Pack carburization was carried out in a steel container with an internal volume of $200 \mathrm{~cm}^{3}$. The container was filled by volume, with $140 \mathrm{~cm}^{3}$ of carburizing compounds, and the titanium samples were placed within the carburizing compound as shown previously in Ref 20. After carburization, the samples were slightly polished to remove the loosely deposited dirt on the surface, followed by ultrasonic cleaning for $15 \mathrm{~min}$ in methanol.

In order to determine the most effective carburizing conditions, both the process temperature and the composition of the carburizing compound were investigated.

The initial composition of the carburizing mixture was the same as that used for traditional steel carburization. The composition of the pack was $70 \%$ carbon and $30 \%$ energizer ( Ref 21$)$. The carbon was in the form of finely ground hardwood charcoal (C), and the energizer was made up of: Barium carbonate $\left(\mathrm{BaCO}_{3}\right)$, sodium carbonate $\left(\mathrm{Na}_{2} \mathrm{CO}_{3}\right)$ and calcium carbonate $\left(\mathrm{CaCO}_{3}\right)$ in the ratio of $3: 2: 1$ ( Ref 21). This pack was used as a starting point to determine the most effective temperature for the carburization process to take place. The duration of the temperature testing was set to $20 \mathrm{~h}$; the samples would also be allowed to furnace cool. The titanium samples were subjected to temperatures of $625,725,825$ and $925^{\circ} \mathrm{C}$. These temperatures were chosen as thermal oxidation has been proven to be effective at this temperature range. These samples were then tribologically tested in order to determine the most effective temperatures for producing a wear resistant coating.

Once the optimal temperature had been determined using the standard steel pack composition, the carburizing compound composition was varied at the defined optimal temperature for a duration of $20 \mathrm{~h}$. The composition of the energizer remained the same, but the ratio of energizer to carbon was investigated. The energizer percentage was varied from $30-50 \%$, samples were then tribologically tested to determine the most wear resistant. Table 1 summarizes all the pack 
carburizing conditions investigated in this study, with a detailed breakdown of the carbonate ratios.

Table 1

Summary of the pack carburizing conditions used in this study

\begin{tabular}{|c|c|c|c|c|c|}
\hline \multirow{2}{*}{ Optimization type } & \multirow{2}{*}{ Temperature, ${ }^{\circ} \mathrm{C}$} & \multicolumn{4}{|c|}{ Pack ratio } \\
\hline & & C & $\mathrm{BaCO}_{3}$ & $\mathrm{Na}_{2} \mathrm{CO}_{3}$ & $\mathrm{CaCO}_{3}$ \\
\hline \multirow{4}{*}{ Temp optimization } & 625 & \multirow{4}{*}{14} & \multirow{4}{*}{3} & \multirow{4}{*}{2} & \multirow{4}{*}{1} \\
\hline & 725 & & & & \\
\hline & 825 & & & & \\
\hline & 925 & & & & \\
\hline \multirow{3}{*}{ Pack optimization } & \multirow{3}{*}{925} & 14 & 3 & 2 & 1 \\
\hline & & 9 & 3 & 2 & 1 \\
\hline & & 6 & 3 & 2 & 1 \\
\hline
\end{tabular}

Phase changes caused by the carburization process were investigated by a Bruker D8 Advance x-ray diffractometer (XRD) using $\mathrm{Cu}-\mathrm{K}_{\alpha 1}$ radiation. The chemical composition with relation to depth was also measured using a glow discharge optical spectroscopy (GDOS). Structural layers were evaluated using the ball-cratering technique, where a circular crater was made by rotating a steel ball with a diameter of $25.4 \mathrm{~mm}$. Ball-craters can reveal the structural changes with depth in the near-surface region at a much magnified view. Microstructural features of the samples were inspected using an optical microscope and a Carl Zeiss EvoHD 15 scanning electron microscope (SEM). The treated samples were etched using a concentrated sulfuric acid $\left(\mathrm{H}_{2} \mathrm{SO}_{4}\right)$ solution at a temperature of $100^{\circ} \mathrm{C}$.

Dry sliding friction and wear tests were carried out using a pin-on-disk tribometer manufactured by Teer Coatings Ltd. During the test, the sample was rotated against a stationary alumina $\left(\mathrm{Al}_{2} \mathrm{O}_{3}\right.$, Grade 25$)$ ball with a diameter of $8 \mathrm{~mm}$ manufactured by Spheric Trafalgar bearings. Alumina was chosen due to its high hardness and low reactivity. The rotation speed of the sample was set to $60 \mathrm{rpm}$ for a total duration of 
$3600 \mathrm{~s}$. The coefficient of friction (COF) was recorded continuously, via a computerized data logger and acquisition system during the sliding wear process. The contact loads employed in this study were as follows: 5, 10, 20 and $40 \mathrm{~N}$. These loads correspond to initial maximum Hertzian contact pressures of 766.6, 965.8, 1216.9 and 1533.2 MPa, respectively. The wear track diameter was set to $9 \mathrm{~mm}$, resulting in a sliding speed of $2.8 \mathrm{cms}^{-1}$ and a total sliding distance of $102 \mathrm{~m}$ for each test. All tests were carried out without lubrication, at room temperature $\left(20^{\circ} \mathrm{C}\right)$ and ambient humidity. The wear depth from each sample was analyzed using a SJ-400 stylus profilometer, and the wear rate was calculated using Eq $+W=V / d_{s}$, where $V$ is the wear track volume and $d_{\mathrm{s}}$ is the sliding distance. All tests were duplicated and the mean results are presented.

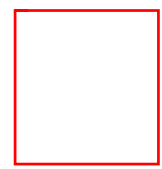

\section{Results and Discussion}

\section{The Effect of Temperature on the Carburization Process}

This section investigates the effect of temperature on the carburization of titanium with limited oxygen diffusion. An initial composition of the carburizing mixture is as discussed in the experimental section of this study. Temperatures of $625,725,825$ and $925^{\circ} \mathrm{C}$ were instigated with the carburization duration fixed to $20 \mathrm{~h}$ and then allowed to furnace cool.

\section{Layer Morphology}

To understand the process temperatures impact on the subsurface structure, the samples were cut to produce cross sections. The cross sections were then nickel plated and mounted in resin. The nickel plate is used to define dark surface films against the resin mount. SEM images (Fig. 1) reveal the resulting structure produced by the carburizing process.

Fig. 1 
SEM images showing the cross-sectional structure after pack carburization for $20 \mathrm{~h}$ at temperatures of: (a) $625^{\circ} \mathrm{C}$, (b) $725^{\circ} \mathrm{C}$, (c) $825^{\circ} \mathrm{C}$ and (d) $925^{\circ} \mathrm{C}$

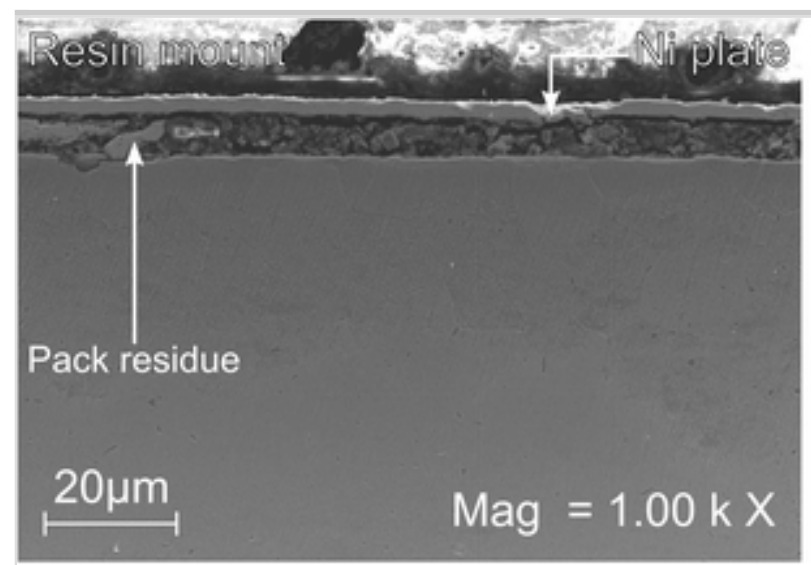

(a)
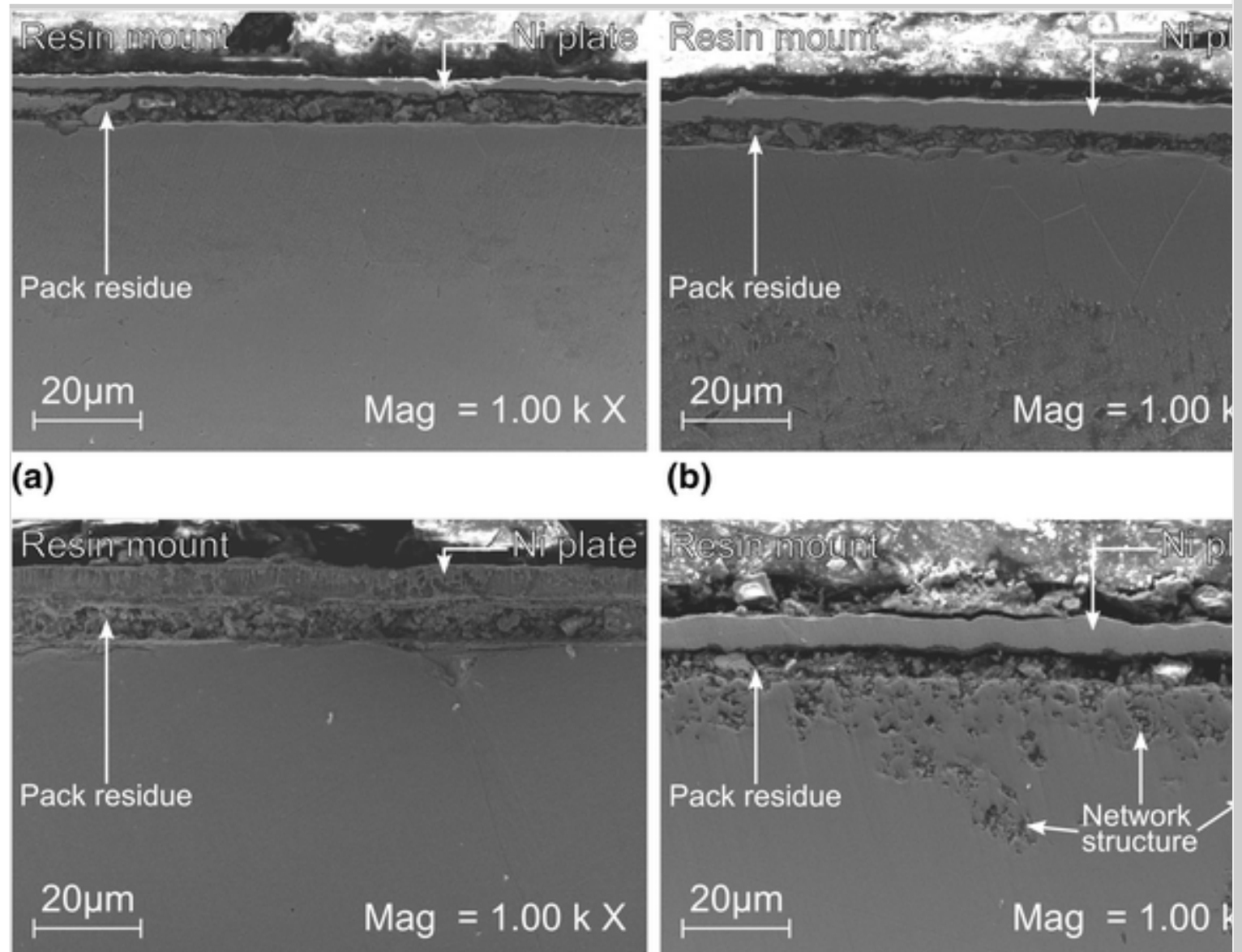

(b)

(c)

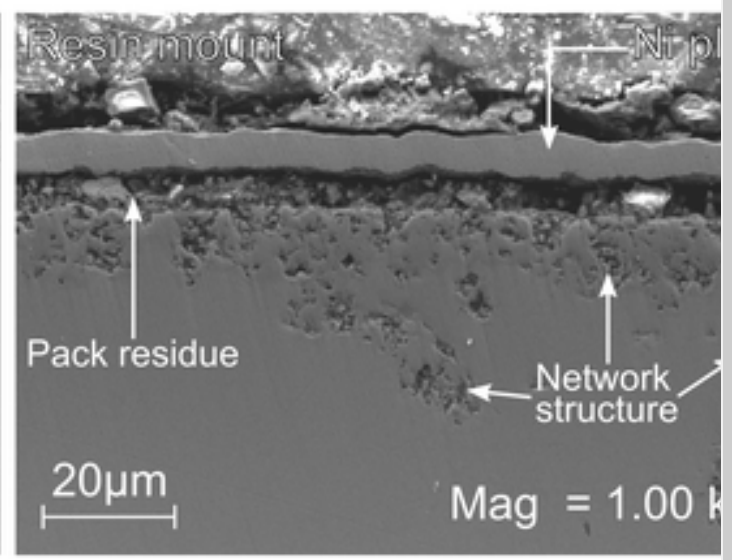

(d)

The SEM cross-sectional images displayed in Fig. 1 show that all the samples treated below $925^{\circ} \mathrm{C}$ are all very similar in appearance. The images show there is a thick pack residue at the surface and what appears to be some cracking of the surface layer, this is then followed by a uniformed subsurface. In contrast, when carburized at a temperature of $925^{\circ} \mathrm{C}$, there is a new structural feature present below the pack residue. This new structure has a network-like appearance and shows uniformity to a depth of $\approx 4.5 \mu \mathrm{m}$, and in places can reach depths of $\approx 16 \mu \mathrm{m}$. The network has no clear defining edge and thus, no obvious place for delamination of this structure to occur, suggesting good adhesion to the subsurface.

Glow Discharge Optical Spectroscopy (GDOS) and Energy Dispersive X-ray Microanalysis (EDX) 
The incorporation of oxygen and carbon into the surface region of the treated titanium was investigated via GDOS composition profile measurements. The carbon profiles shown in Fig. 2(a) show clearly that carbon diffusion was most effective at a temperature of $925^{\circ} \mathrm{C}$. At this elevated temperature, an extended region of carbon-rich titanium is clearly present. For the samples treated below $925^{\circ} \mathrm{C}$, there is a very limited amount of carbon diffusion. From the GDOS profile, it is estimated that carbon penetrated just 1-2 $\mu \mathrm{m}$ compared with over $20 \mu \mathrm{m}$ for the $925{ }^{\circ} \mathrm{C}$ samples.

Fig. 2

Carbon (a) and oxygen (b) concentration profiles measured by GDOS produced by carburization at temperatures of: $625,725,825$ and $925{ }^{\circ} \mathrm{C}$ for $20 \mathrm{~h}$
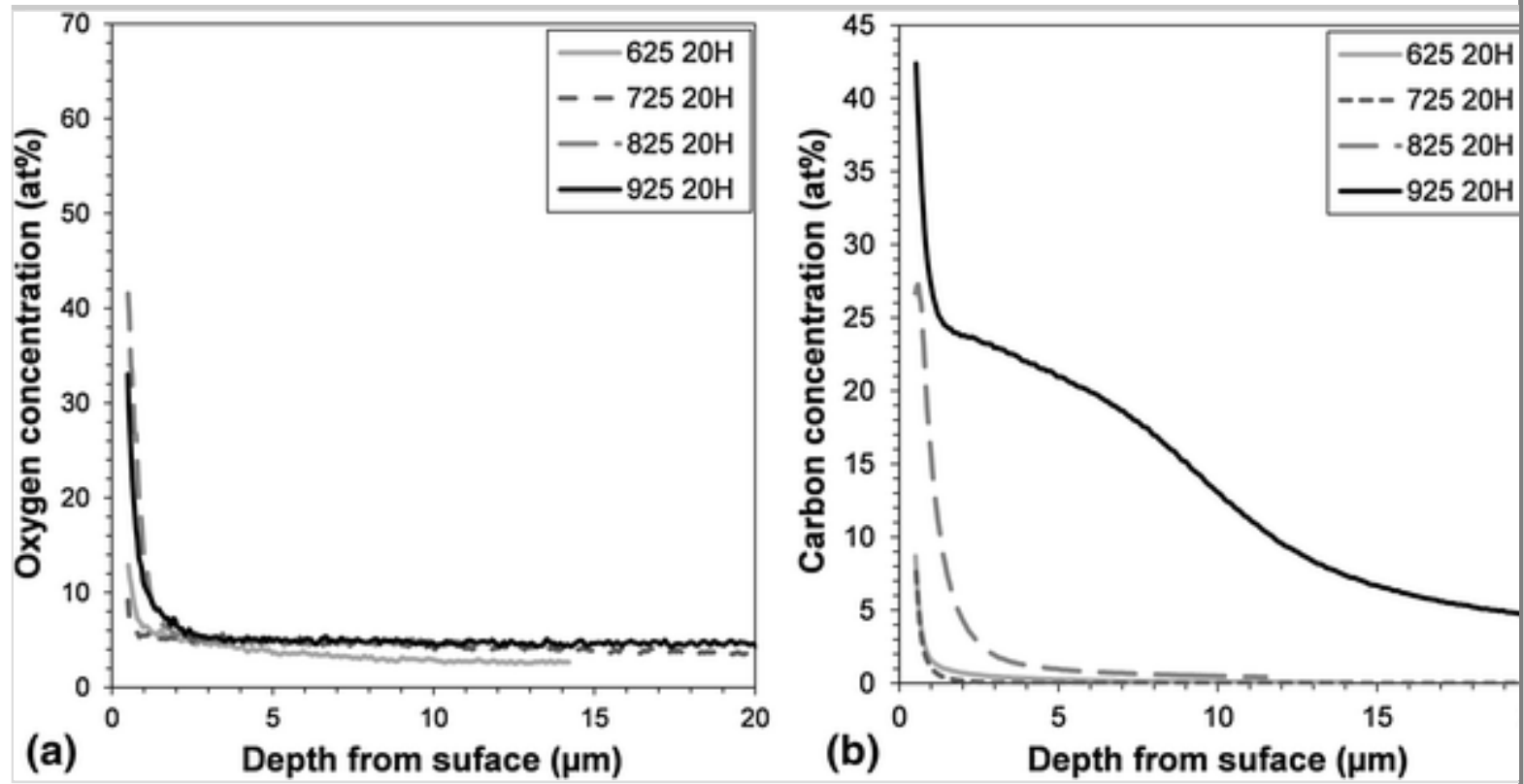

When considering the oxygen diffusion within the treated samples (Fig. 2b), the amount of oxygen is constant throughout the limited depth plots for the samples. This indicates that large-scale oxygen diffusion has occurred. It can be seen that when carburizing was undertaken at $625^{\circ} \mathrm{C}$, the oxygen concentration starts to drop much sooner than that of the samples treated at a higher temperature. This can be attributed to the slow diffusion of oxygen in $\alpha$-Ti, at the relatively low temperature of $625^{\circ}(\operatorname{Ref} 22)$. 
GDOS demonstrates that the network structure identified in Fig. 1(d) could be linked to the increased carbon concentration within the subsurface. The depth of this network structure was measured from the cross sections shown in Fig. 1(d) and was shown to reach a depth of $\approx$ $16 \mu \mathrm{m}$. Carbon has a maximum solubility of 3.3 at.\% within the $\alpha$-Ti substructure (Ref 23). The GDOS data suggest that titanium carbide (TiC) precipitation could be occurring at depths of up to $\approx 16-17 \mu \mathrm{m}$ from the surface. This is in direct correlation to the cross-sectional images and suggests the nature of the network structure would be some form of titanium carbide/titanium oxycarbide.

EDX spectroscopy was undertaken for the $925{ }^{\circ} \mathrm{C}$ sample using a Carl Zeiss EvoHD 15 scanning electron microscope (SEM). A detailed SEM image of the network structure just below the samples surface was captured (Fig. 3a); this image shows the network structure to be nonporous and crystalline in nature. The region was mapped for its chemical composition with the resulting spectrum of elements displayed in Fig. 3(b). The spectrum shows clear peaks for both carbon and oxygen within the structure. When the atomic percentage for both carbon (35.96\%) and oxygen (21.14) are evaluated (see Table 2), demonstrate a clear correlation with the GDOS data from Fig. 2 ean be observed whereby and again confirms there-is-to besignificantly more carbon than oxygen within this network like structure.

\section{Fig. 3}

EDX investigation into the network-like structure with (a) showing a $10 \mathrm{k}$ magnification image of the network structure and (b) showing the EDX spectrum of the region 


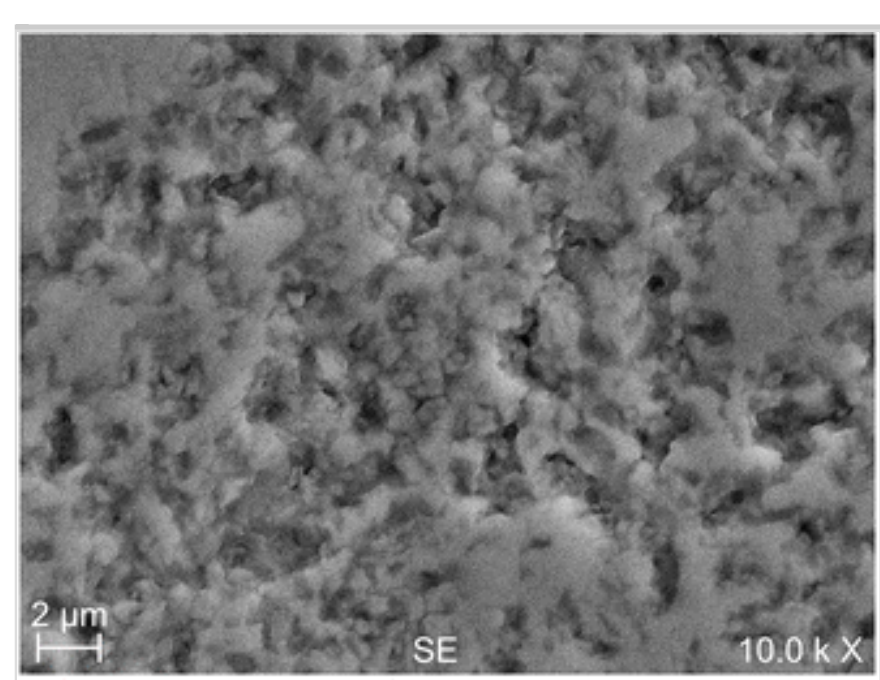

(a)

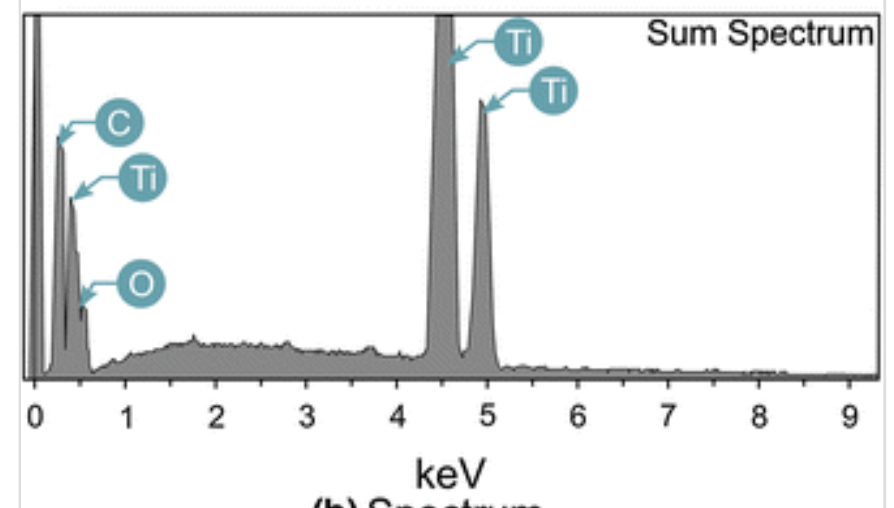

(b) Spectrum

Table 2 Remove table 2

EDX composition data generated from the network structure region shown in Fig. 3

\begin{tabular}{|l|l|}
\hline Element & Atomic, \% \\
\hline Ti & 42.9 \\
\hline C & 35.96 \\
\hline O & 21.14 \\
\hline
\end{tabular}

\section{X-ray Diffraction (XRD)}

X-ray diffraction analysis was undertaken for the samples treated at 925 and $825^{\circ} \mathrm{C}$. Figure 4 clearly shows the presence of $\mathrm{TiC}$ in the sample treated at $925^{\circ} \mathrm{C}$. Therefore, looking at the XRD, GDOS (Fig. 2) and images in Fig. 1, these strongly suggest the network-like structure is linked to the presence of $\mathrm{TiC}$. It can be observed via the diffraction data 
that the samples treated at $925{ }^{\circ} \mathrm{C}$ have much stronger TiC signal intensity than the samples treated at $825^{\circ} \mathrm{C}$. This seems to confirm that carbon diffusion happens at an increased rate when treated at $925^{\circ} \mathrm{C}$. XRD also demonstrates the presence of oxygen within the titanium subsurface. The $\alpha$-Ti peaks of the treated samples are shifted to a smaller $2 \theta$ angle, showing that lattice expansion has occurred due to oxygen dissolution. This lattice expansion has been observed by numerous authors $(\operatorname{Ref} 11,19,24)$.

Fig. 4

$\mathrm{X}$-ray diffraction patterns generated from samples carburized at temperatures of 825 and $925^{\circ} \mathrm{C}$ for $20 \mathrm{~h}$ against untreated titanium

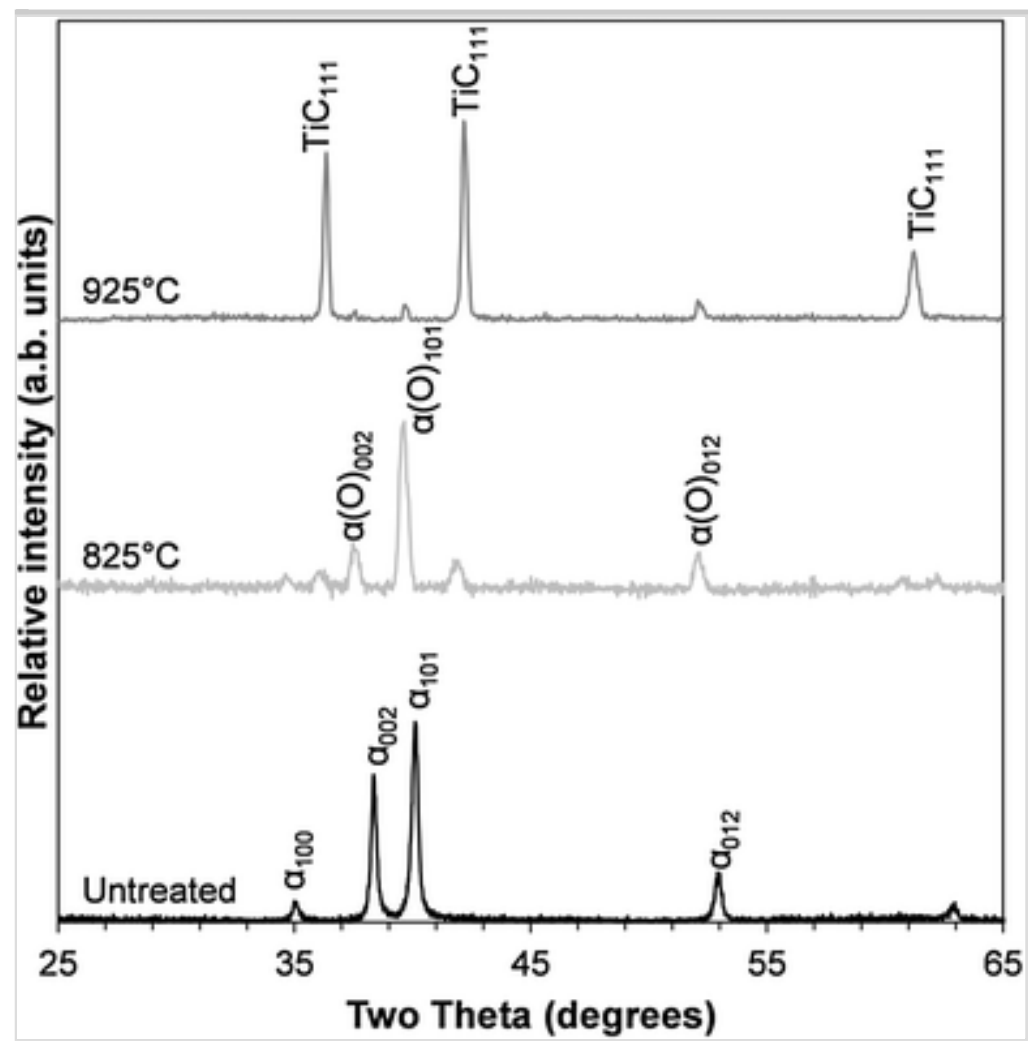

Surface Hardness Measurements

Surface hardness measurement was taken using an Indentec ZHV microhardness machine and is presented in Fig. 5. The surface hardness of untreated titanium was measured as a baseline reference and resulted in a consistent hardness of $\approx 300 \mathrm{HV}$, independent of applied load. The surface measurements taken for the PCOD samples treated at the various temperatures show a significant increase in both surface and 
subsurface hardness. Hardness values show a clear correlation between increased temperature and increased hardness, with the sample treated at $925^{\circ} \mathrm{C}$ showing peak hardness values that are 4 times greater than that of the untreated sample. It is interesting to see that the initial high surface hardness drops of much faster in samples treated at temperatures below $925^{\circ} \mathrm{C}$. Looking at the XRD data (Fig. 4) and the cross-section presented in Fig. 1, this increase in surface hardness must be linked to the presence of the TiC network structure.

\section{Fig. 5}

Surface hardness profiles generated by the samples treated using the PCOD temperatures of $625-925^{\circ} \mathrm{C}$ for $20 \mathrm{~h}$

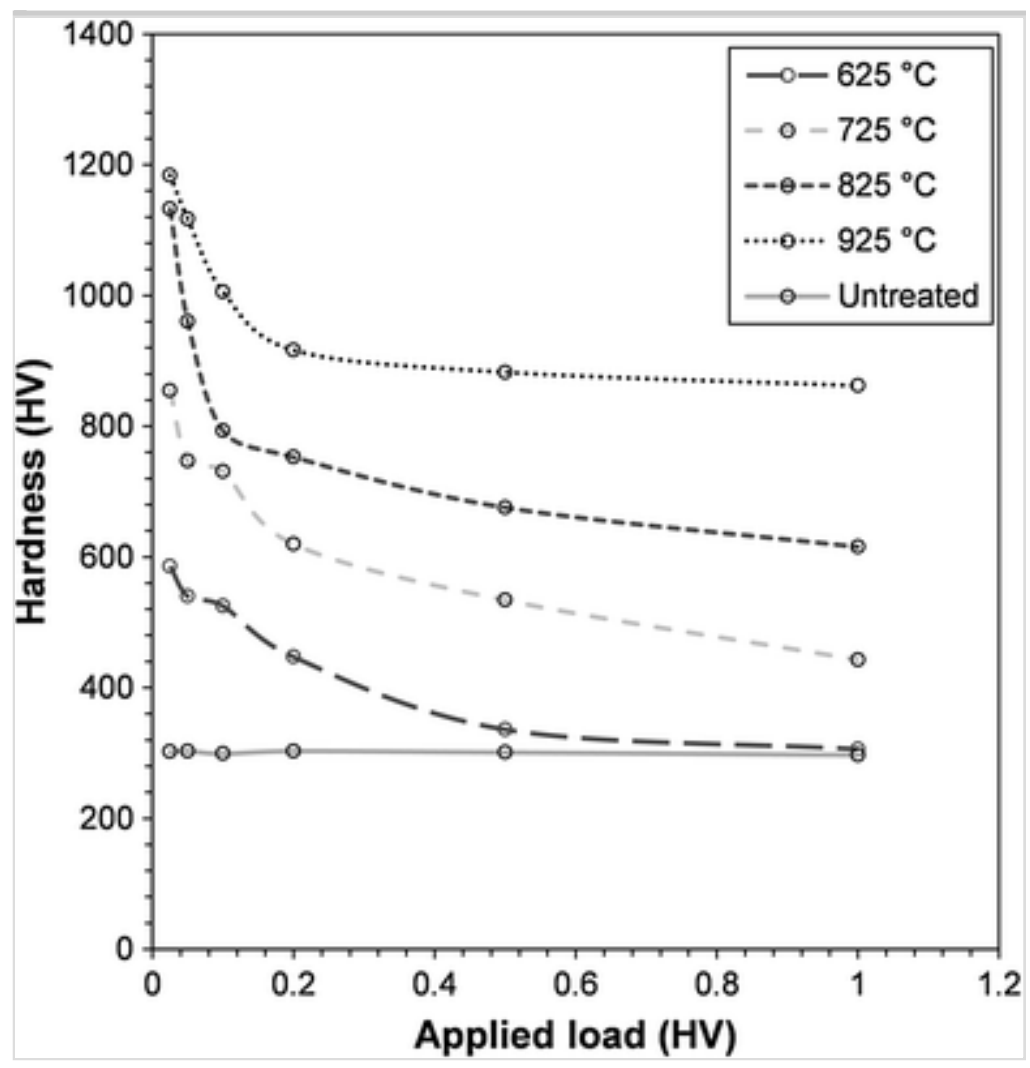

Figure 5 also shows substantial subsurface hardness, as the load is increased we see the treated samples show a significant increase in hardness over that of untreated Ti. When this is linked to the GDOS data displayed in Fig. 2, we can attribute the high surface hardness present within the samples to the high carbon content present within the close sub surface. The increases oxygen level in the extended subsurface can be attributed to the increase hardness present in the 
surface profiles at the higher loads. This combination of high surface hardness and increased load bearing capacity are an attractive combination for improving the tribological response of a material.

\section{Tribological Response}

Friction Behavior

The main aim of this study is to improve the tribological response of the titanium samples. Therefore, when characterizing the new treatment process, the tribological performance is of great importance. All the pack carburized samples were tribologically tested for $1 \mathrm{~h}$ under loads of 5, 10, 20 and $40 \mathrm{~N}$, until film failure was observed. The coefficient of friction (COF) was recorded, and the resulting wear rates were measured. Figure 6 shows the frictional response for the various treatment temperatures at their failure loads.

\section{Fig. 6}

Coefficient of friction (COF) curves recorded for samples pack carburized at $625,725,825$ and $925{ }^{\circ} \mathrm{C}$ for $20 \mathrm{~h}$ under failure contact loads

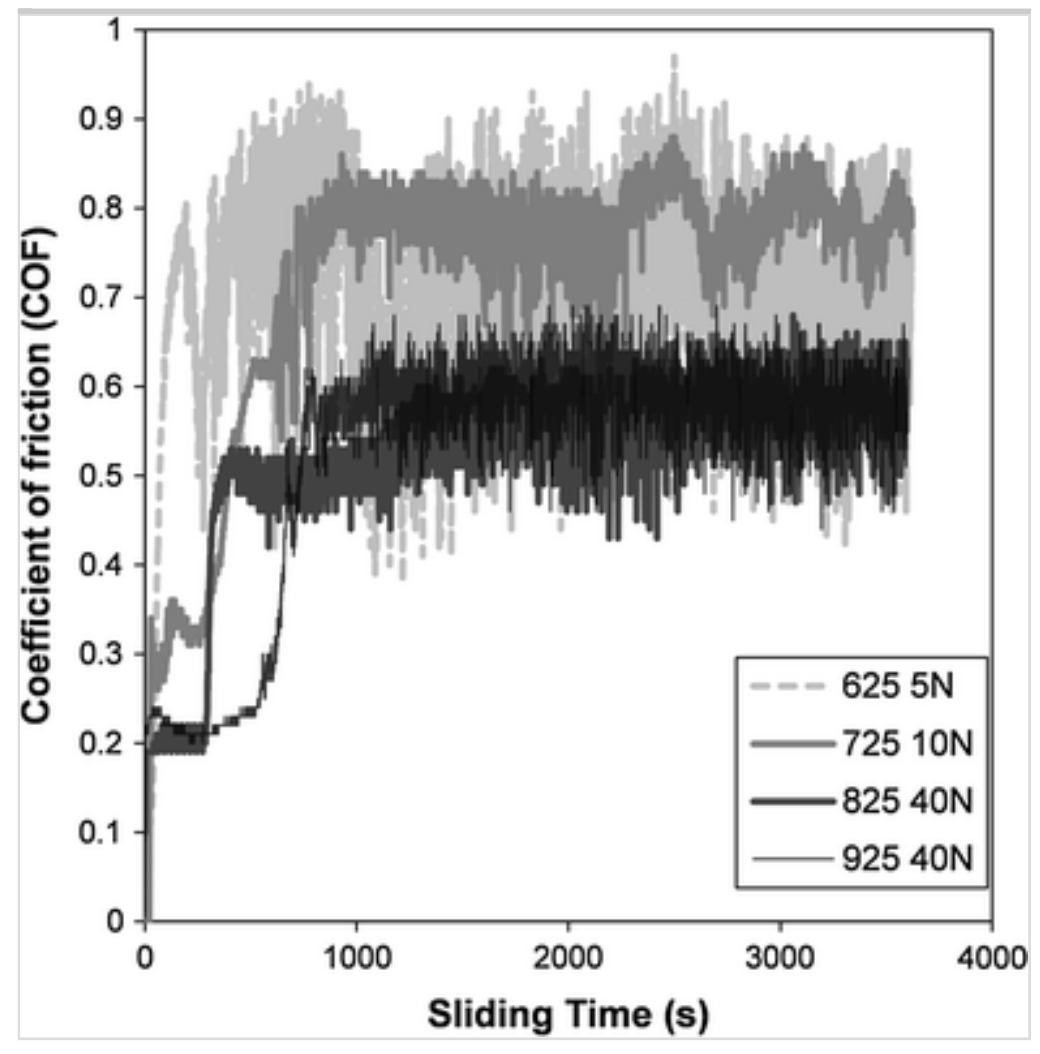


Figure 6 shows that titanium treated at $625^{\circ} \mathrm{C}$ was unable to withstand a load of $5 \mathrm{~N}$ without exhibiting high friction for the duration of the test. Any surface film present is quickly removed with the COF, then becoming consistent at a value of $\approx 0.8$. The COF observed is higher than 0.6 associated with pure titanium and more in-line with that of oxygen-rich titanium ( $\operatorname{Ref} 22,25)$. Ti treated at $725^{\circ} \mathrm{C}$ was able to withstand a load of $10 \mathrm{~N}$ for $\approx 250 \mathrm{~s}$, with a low COF $(\mu<0.4)$. There is then a period of increasing friction, as the film is removed until the COF reaches 0.8. Again, this COF is consistent with that of oxygen-rich Ti in sliding contact with alumina. When the temperature was increased to $825^{\circ} \mathrm{C}$, the Ti was able to withstand loads of 5,10 and $20 \mathrm{~N}$. However, when the load was increased to $40 \mathrm{~N}$, the treated Ti initially responded with a low $\operatorname{COF}(\mu \approx 0.2)$, but then subsequent film breakdown and removal resulted in the COF increasing to 0.6. The titanium treated at $925^{\circ} \mathrm{C}$ was able to withstand a load of $5 \mathrm{~N}, 10 \mathrm{~N}$ and $20 \mathrm{~N}$. When tested under a load of $40 \mathrm{~N}$, the sample produced low friction $(\mu=0.2)$ for a longer duration than any of the other samples $(t \approx$ $600 \mathrm{~s}$ ). Both the 825 and $925^{\circ} \mathrm{C}$ samples show a sudden rise in friction, although they did not reach the same level of COF, as that experienced by samples treated at 625 and $725^{\circ} \mathrm{C}$. The reduced COF encountered, once the ODZ has been exposed, can be explained by the extremely high contact load. This will result in increased oxidative wear and surface hardening. A study conducted by Meier et al. (Ref 26) has shown that the effect plastic deformation has on reducing the observed $\mathrm{COF}$ in titanium.

The initial low COF observed can be related to the amount of carbon within the titanium. It is clear that the samples with more carbon diffusion are able to withstand higher loads for longer periods of time. It is interesting to note that the titanium treated using $925^{\circ} \mathrm{C}$ has a network-like structure (Fig. 1d). This feature resulted in the best tribological response of all the samples, with low friction and good adhesion.

\section{Wear Rates}

The measured wear rates $\left(\mathrm{mm}^{3} / \mathrm{m}\right)$ as a function of contact load for all the test samples are shown in Fig. 7, using Eq 1. Several observations 
can be made: Firstly, for each test sample, the wear rate increased with increasing load. There is an abrupt rise in the wear rate for all the carburized samples when a critical load was tested. This corresponds with the increased COF observed by the removal of any surface carbide/oxycarbide layer present within the surface contact area. Secondly, as long as wear occurred only in the carbide/oxycarbide layer, the COF and wear rate remain very low, three to four orders of magnitude lower than that of the untreated titanium. Finally, when the carburized layer was worn through and wear occurred mainly in the diffusion zone, for example: $5 \mathrm{~N}, 625^{\circ} \mathrm{C} ; 10 \mathrm{~N}, 725^{\circ} \mathrm{C} ; 40 \mathrm{~N}, 825^{\circ} \mathrm{C}$; $40 \mathrm{~N}, 925^{\circ} \mathrm{C}$, an abrupt increase in both friction (Fig. 6) and wear is observed.

Fig. 7

Wear rate of carburized titanium produced at various temperatures and loads

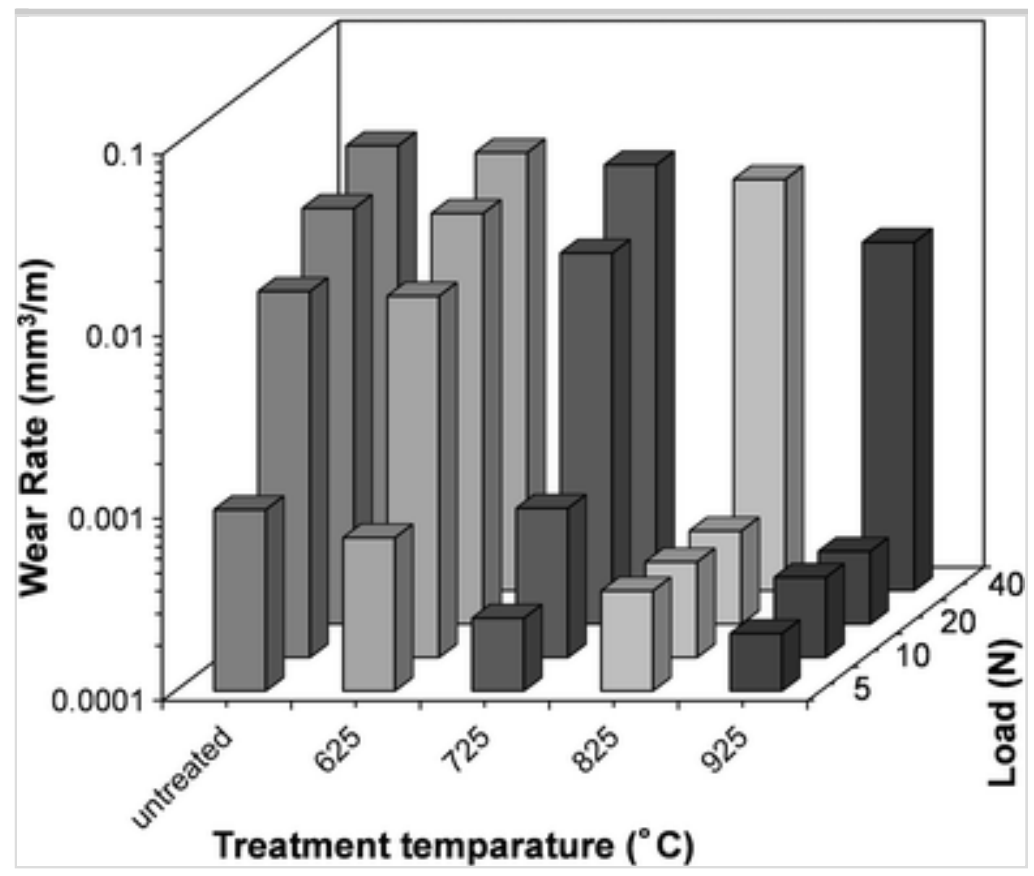

When the carburized Ti is compared to untreated Ti, all the carburized samples exhibited lower wear rates, even when the carbide network layer was completely removed at high loads. The hardened oxygen diffusion zone exhibited very high and unstable friction $(\mu \approx 0.6)$, in both the $625^{\circ} \mathrm{C}$ sample and the $725^{\circ} \mathrm{C}$ sample. However, both experienced a reduced wear rate when compared to CP-Ti. Thus, the 
diffusion zone is also effective at reducing wear; this is more pronounced under lower contact loads. This phenomenon has been seen previously in a thermal oxidation study (Ref 11).

\section{Mechanisms Involved in Producing Optimal Film Performance} In a previous work, the mechanisms by which titanium is carburized were discussed (Ref 20). It was shown that in order for carbon to diffuse in titanium, a constant supply of carbon monoxide (CO) is required. During pack carburizing, $\mathrm{CO}_{2}$ is generated through the thermal decomposition of the carbonates. The decomposition of $\mathrm{BaCO}_{3}, \mathrm{CaCO}_{3}$ and $\mathrm{Na}_{2} \mathrm{CO}_{3}$ occurs at temperatures $>800{ }^{\circ} \mathrm{C}$ (Ref 27-30). Substantial carburization will only begin to occur once the temperature exceeds $800{ }^{\circ} \mathrm{C}$. It is also reasonable to assume that any oxygen within the pack container will react with titanium at the elevated temperatures. Thermal oxidation of titanium is a reaction that proceeds with great vigor at temperatures above $600{ }^{\circ} \mathrm{C}$. Oxidation for a short duration at temperatures greater than $700{ }^{\circ} \mathrm{C}$ can result in large-scale titanium dioxide (rutile) formation (Ref 12, 31, 32). Once all the available oxygen has been exhausted, oxygen diffusion into the subsurface can continuously occur. It has been previously shown by Dong and Li (Ref 19) that prolonged heating (in a vacuum furnace) after initial oxidation allows for the creation of a large oxygen diffusion zone, through the reduction of the $\mathrm{TiO}_{2}$ surface film. GDOS (Fig. 2b) and XRD (Fig. 4) analyses confirm that oxygen diffusion has occurred to form an extended oxygen diffusion zone.

It is believed that initially the oxidation of titanium can impede the rate of carburization. However, $\mathrm{TiO}_{2}$ itself can be converted into TiC during the carburization process ( $\operatorname{Ref} 20,33)$. Once the production of $\mathrm{CO}$ is at a sufficient level, carburization will occur. There are multiple reactions that could take place in order for carbon to react with and to diffuse into the oxygen-rich titanium. However, using XRD analysis (Fig. 4), TiC has been shown to be the predominant phase, although titanium oxycarbide phases cannot be discounted.

The rate at which carbon diffusion within titanium is dependent on crystal phase, with $\beta$-Ti being faster than $\alpha$-Ti. $\beta$-Ti has a pre 
exponential diffusion coefficient $\left(\mathrm{D}_{0}\right)$ of $27.27 \times 10^{-4} \mathrm{~m}^{2} \mathrm{~s}$ compared with that of $\alpha$-Ti of $8.63 \times 10^{-4} \mathrm{~m}^{2} \mathrm{~s}$ (Ref 23). Clearly, this shows that carbon diffuses faster into $\beta$-Ti. When titanium is carburized at a temperature of $925^{\circ} \mathrm{C}$, the beta phase would normally be expected. However, using a pack carburization technique that allows limited oxygen diffusion, a stabilization of the alpha phase can be expected. This will increase the transition temperature to the beta phase. This increase will be dependent on the amount of oxygen present within the titanium substructure. Using the Ti-O phase diagram (Ref 34 ), it can be seen that the transition temperature is $\approx 960{ }^{\circ} \mathrm{C}$ when titanium is oxygen rich to the levels observed via GDOS (Fig. 2a). Therefore, the transition temperature can reasonably be discounted as the mechanism by which increased carbon diffusion occurs at a temperature of $925^{\circ} \mathrm{C}$.

Taking into account the decomposition temperatures of the carbonates and the phase transition temperatures of titanium, it is believed that the decomposition of the carbonates and the generation of carbon monoxide are the determining factors in the rate of carbon diffusion. When the temperature is below $925^{\circ} \mathrm{C}$, the rate of carbonate decomposition happens relatively slowly, inhibiting the dissolution of carbon into titanium. Therefore, a temperature around $925^{\circ} \mathrm{C}$ is required for a fast and effective treatment. Accordingly, all further treatments were conducted at $925^{\circ} \mathrm{C}$.

\section{The Effect of Pack Composition on Film Growth}

In section 3.1, it was demonstrated that $925^{\circ} \mathrm{C}$ was the most effective temperature for generating a wear resistant film by inducing carbon and oxygen diffusion into titanium. It was also discussed how the decomposition of the carbonates allowed for the formation of carbon monoxide (CO) within the carburizing container. This is seen as one of the major contributing factors leading to the formation of the $\mathrm{TiC}$ network structure seen in Fig. 1(d). All tests in the previous section were carried out using a pack composition of $70 \mathrm{wt} . \%$ carbon and 30 wt. $\%$ carbonates. It was shown that the amount of $\mathrm{TiC}$ produced was directly related to the wear rate of the treated titanium. 
Another way to increase the rate of carburization is to increase the amount of carbonates that can decompose to form CO. Using the same 20-h duration, the effect of the pack composition was investigated.

Carbonate percentages of 30,40 and $50 \%$ were investigated, in the ratio of barium carbonate $\left(\mathrm{BaCO}_{3}\right) 3$ part, sodium carbonate $\left(\mathrm{Na}_{2} \mathrm{CO}_{3}\right) 2$ part and calcium carbonate $\left(\mathrm{CaCO}_{3}\right) 1$ part, as highlighted in Table 3.

\section{Table 3}

Variation in carbon and carbonate percentage used within the pack

\begin{tabular}{|l|l|l|}
\hline Carbon, wt.\% & Carbonates, wt. $\%$ & Ratio $\left(\mathbf{C}: \mathbf{B a C O}_{3}: \mathbf{N a}_{2} \mathbf{C O}_{3}: \mathbf{C a C O}_{3}\right)$ \\
\hline 70 & 30 & $14: 3: 2: 1$ \\
\hline 60 & 40 & $9: 3: 2: 1$ \\
\hline 50 & 50 & $6: 3: 2: 1$ \\
\hline
\end{tabular}

\section{Structural Investigation}

Cross-sectional images of the carburized samples were produced, to understand how the structure is impacting on the tribological response of the samples. An example of these images can be seen for the $50 \%$ carbonate sample in Fig. 8(a). The etched cross section gives a good indication as to the extent oxygen diffusion. The cross-sectional images indicated that the carburizing compound has little, if any, effect on the rate of oxygen diffusion. Measurements of the oxygen diffusion zone (ODZ) show a consistent depth of $\approx 195 \mu \mathrm{m}$ for all samples. Therefore, the ODZ is not greatly affected by the percent of carbonates in the carburizing compound; Fig. 9 shows the recorded values of the ODZ depth.

\section{Fig. 8}

Optical micrograph showing the etched cross-sectional morphology and surface ball crater for pack carburized titanium treated at $925{ }^{\circ} \mathrm{C}$ for durations of $20 \mathrm{~h}$ with pack composition of $50 \%$ 


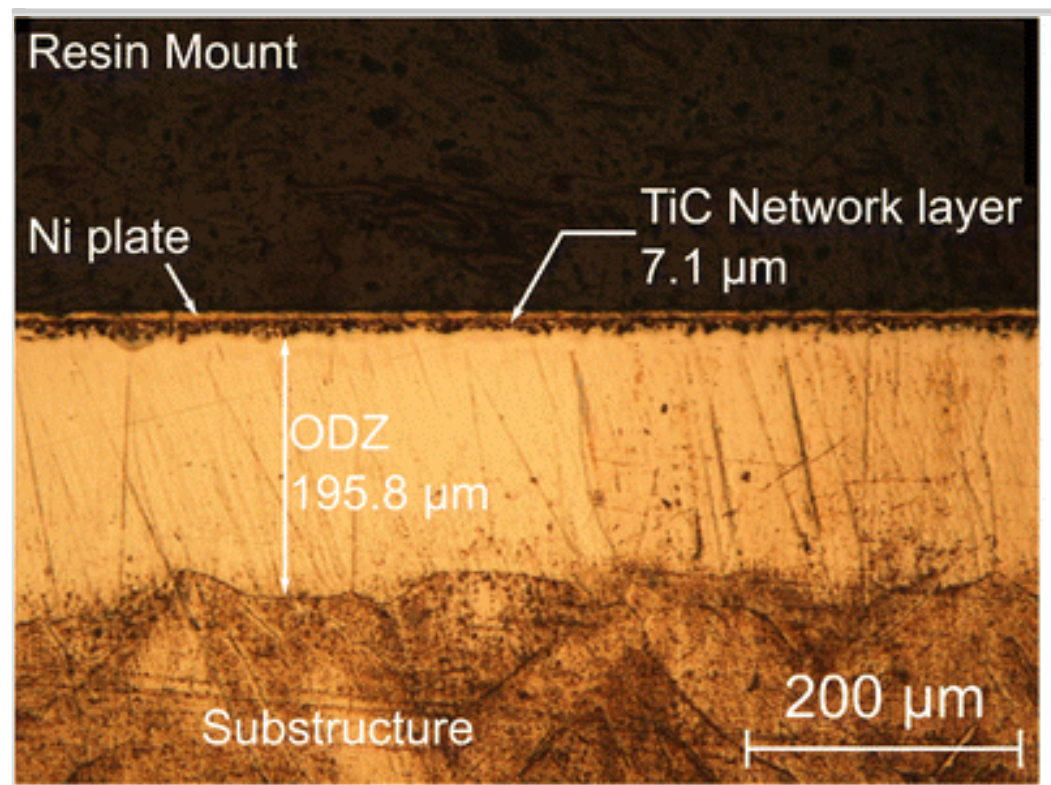

(a)

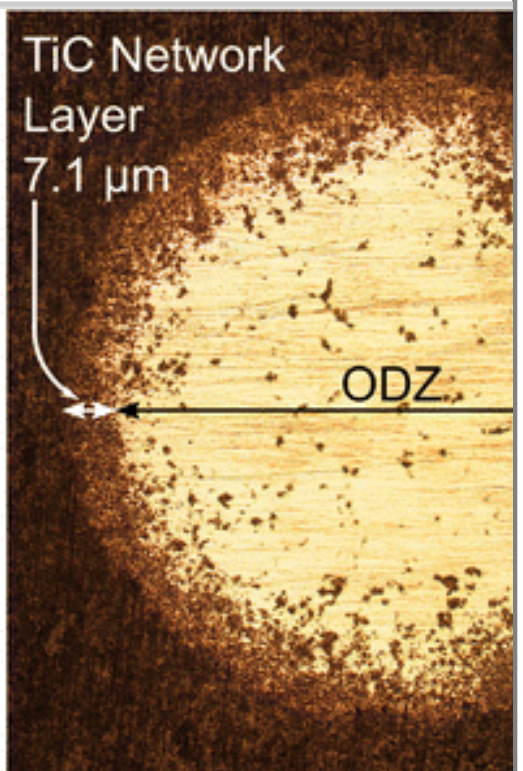

(b)

Fig. 9

Film thickness of the TiC network and ODZ with regard to the carbonate concentration, at a temperature of $925^{\circ} \mathrm{C}$ for durations of $20 \mathrm{~h}$

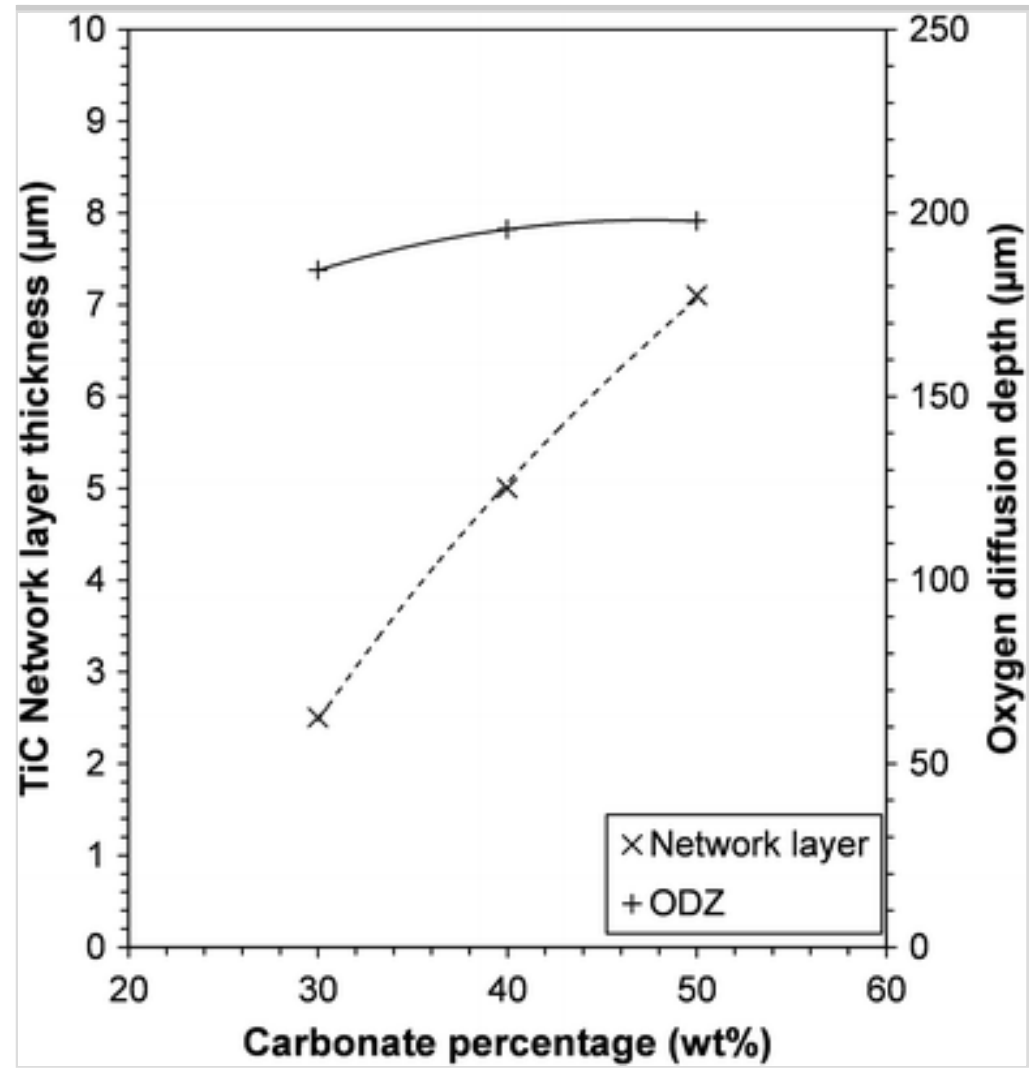


In order to determine the uniformed thickness of the TiC network structure, the ball-cratering technique was employed. An example of this can be seen in Fig. 8(b), for the 50\% sample. Using this technique, the uniformed thickness of the TiC structure is sufficiently measurable. Measurements of the TiC structure taken are displayed graphically in Fig. 9. Figure 9 shows that increasing the carbonate percentage increases the thickness of the TiC layer. The titanium treated with a 1:1 ratio of carbon to energizer produced a TiC layer that just over twice the uniformed thickness $(7.1 \mu \mathrm{m})$ of that created using a pack ratio of $7: 3(2.3 \mu \mathrm{m})$.

\section{Tribological Response}

Frictional Response

The samples were tribologically tested using loads of: 5, 10, 20 and $40 \mathrm{~N}$. When the carburized titanium samples were tested using a contact load of $20 \mathrm{~N}$, all samples survived the test and exhibited a low COF $(\mu$ $<0.3$; Fig. 10a). When tested at $40 \mathrm{~N}$ (see Fig. 10b), it can be seen that the initial friction is very low for all samples. However, when the titanium is carburized in a pack using a $30 \%$ concentration of carbonates; the initial low friction lasts for just $500 \mathrm{~s}$. After the initial low friction zone, breakdown of the TiC network structure occurred, exposing the underlying ODZ and resulting in a high COF $(\approx 0.6)$. When the concentration of carbonates is increased to $40 \%$, the low COF period is extended and lasts for $1500 \mathrm{~s}$. This is again followed by the high friction of the ODZ. Once the carbonate percentage is increased to $50 \%$, the COF remains low $(<0.4)$ for the duration of the test.

Fig. 10

COF curves for the response of PC-Ti $\left(925^{\circ} \mathrm{C}, 20 \mathrm{~h}\right)$ produced under a load of $20 \mathrm{~N}$ (a) and $40 \mathrm{~N}$ (b) for the various pack compositions 

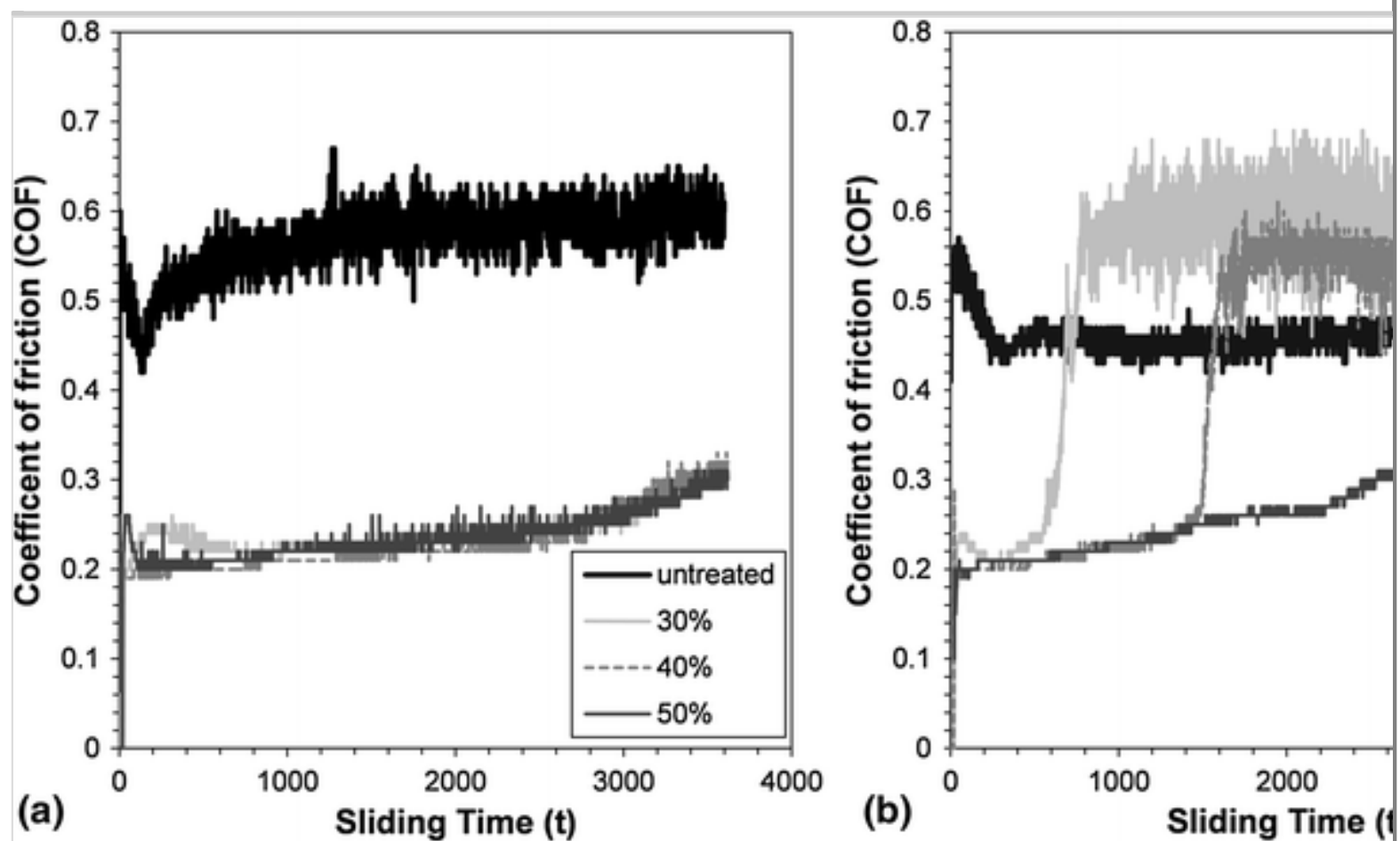

Figure 11 shows the wear track morphology, for the treated samples, these images clearly show the exposure of the ODZ within the wear track for the samples treated using 30\% (Fig. 11a) and 40\% (Fig. 11c) carbonate composition pack. Analysis of the wear track images showed wear occurred through oxidative wear, abrasion and delamination. The ODZ of the pack carburized titanium showed a relatively smooth wear track. This feature is very similar to that of the exposed ODZ of thermally oxidized titanium (Ref 11).

\section{Fig. 11}

Optical and SEM images showing wear track morphology of titanium carburized at $925^{\circ} \mathrm{C}$ for a duration of $20 \mathrm{~h}$ with carbonate percentages of (a-b) $30 \%$, (c-d) $40 \%$ and (e-f) $50 \%$. All tests were conducted using a $40 \mathrm{~N}$ load for $3600 \mathrm{~s}$ 


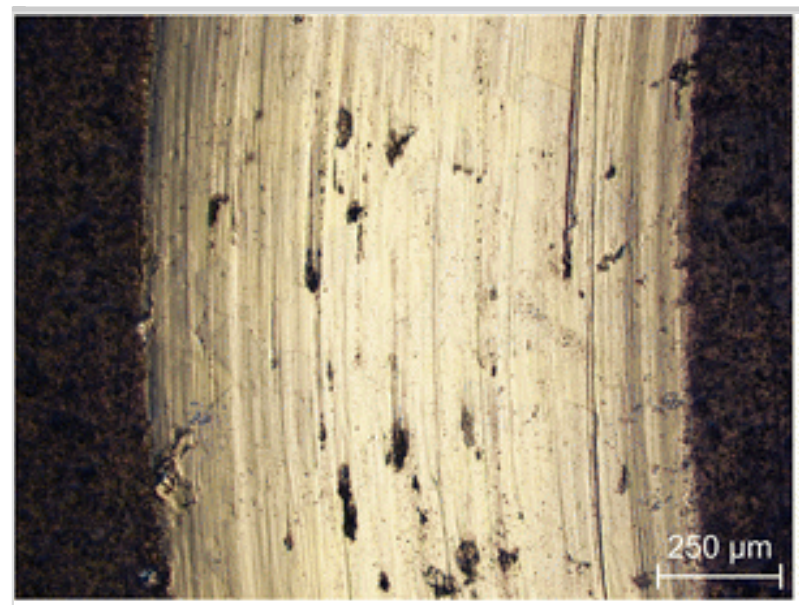

(a)

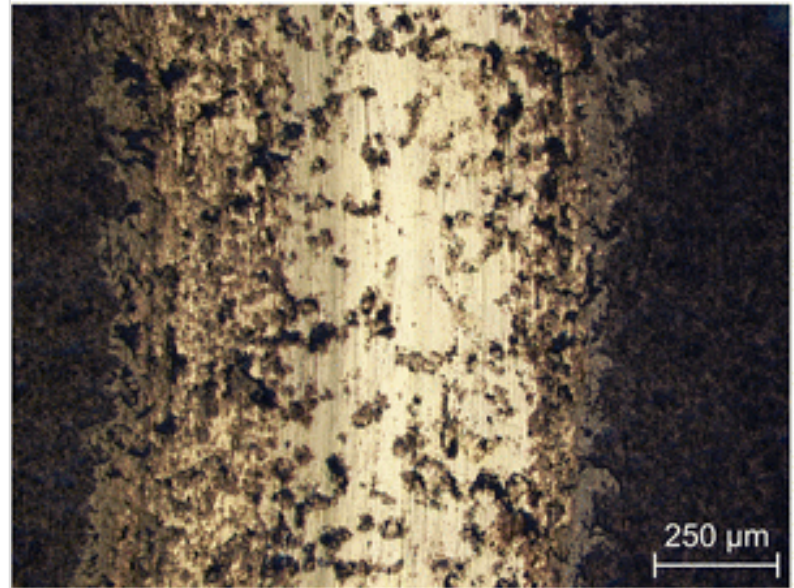

(c)

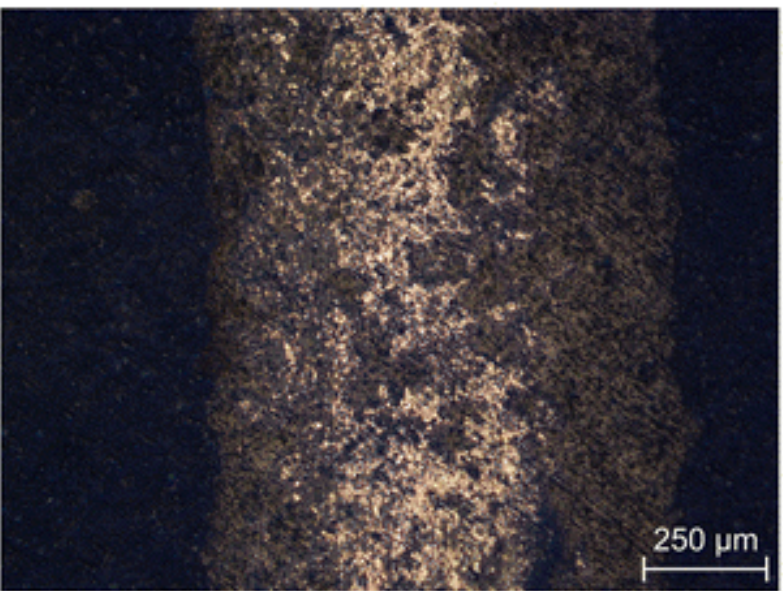

(e)

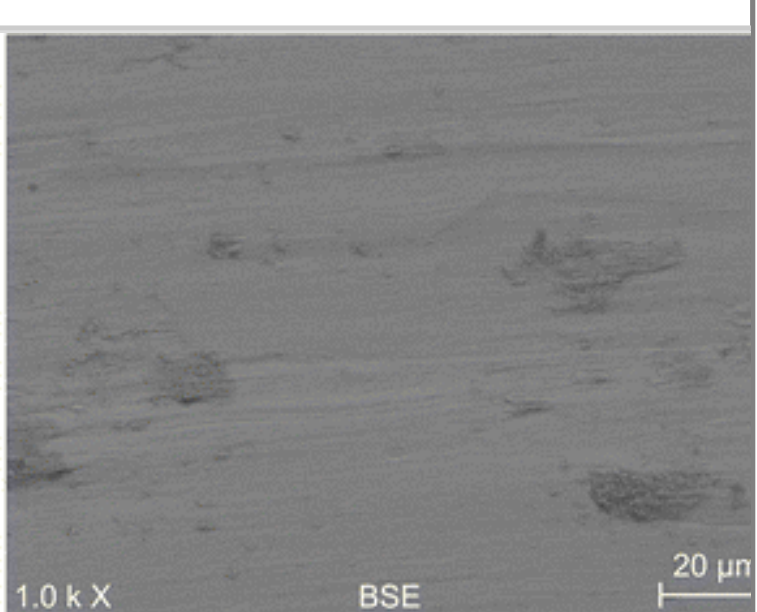

(b)

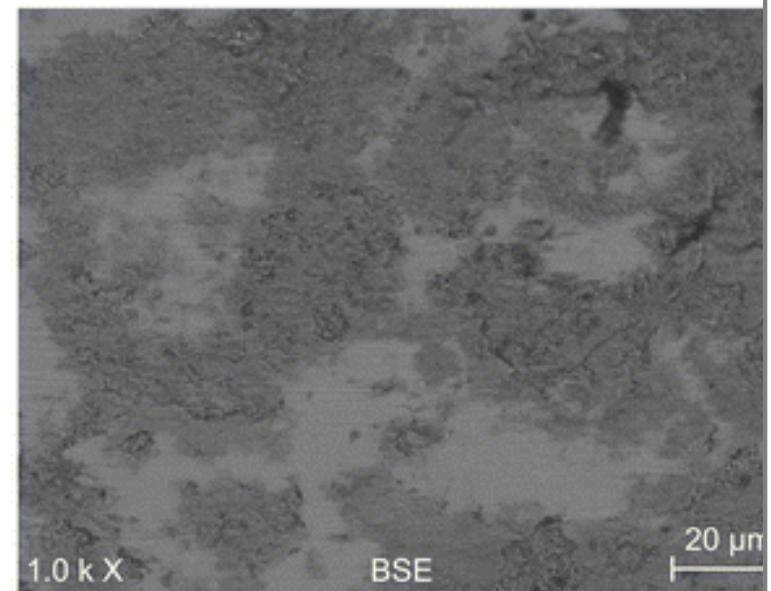

(d)

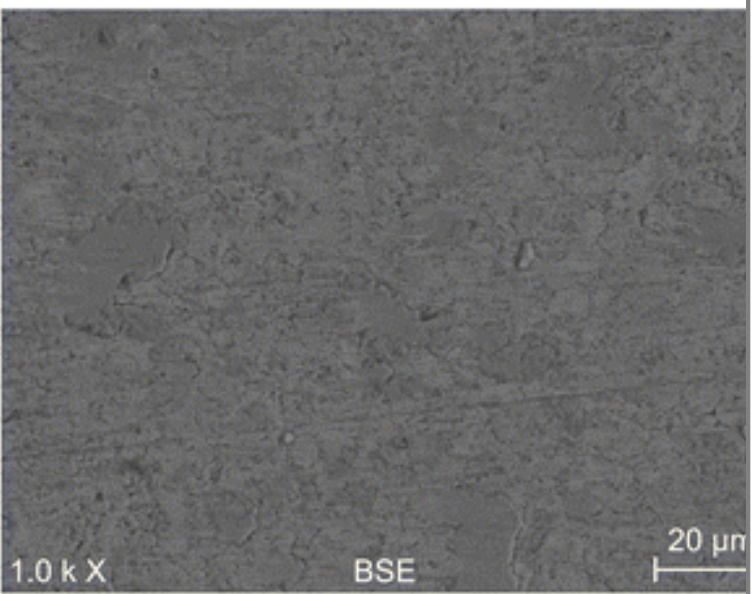

(f)

A key feature observed in the wear tracks of the 30 and $40 \%$ samples is the smooth transition from the surface coating to the wear track profile. Within the wear track, there is no sign of surface shear or interface cracking between the surface and subsurface. This gives a strong indication that the adhesion between the surface film and the substrate 
is very good; this is demonstrated by its ability to withstand very high contact loads.

SEM images of the wear tracks reveal some key characteristics regarding the wear mechanisms. Figure 11(b) shows the wear track morphology of the sample treated with $30 \%$ carbonates. The wear track exhibits an overall smooth appearance with abrasive grooves running parallel to the direction of sliding. There are also regions with $\mathrm{TiC}$ accumulations; these are remnants of the network film and are present due to the varying thickness of the network structure. Although the TiC network has been predominantly removed, the wear track looks substantially different to that expected of pure titanium. Titanium wear is typically dominated by adhesive wear (19); this oxygen-rich region generated during the PCOD shows much reduced adhesive wear, and is far more dominated by abrasion. The sample treated using with $40 \%$ carbonates (Fig. 11d) shows the wear tack to be substantially different from that of the sample treated with $30 \%$ carbonates. Within the wear track, there is substantially more $\mathrm{TiC}$ accumulations interspersed with the exposed ODZ. The TIC network structure shows wear through simple abrasion, resulting in a smooth polished like finish. Where the ODZ is exposed, the dominating wear mechanism is again abrasion, with clearly defined abrasive grooves. The exposure of the ODZ is also exhibited in the friction coefficients recorded in Fig. 10(b).

The samples treated in a 50\% energized pack (Fig. 11e) showed no sign of ODZ exposure. The dominating wear mechanism is that of abrasive polishing, demonstrated by the smoothing of the peaks within the contact zone. The SEM image (Fig. 11f) also confirms that the dominant mechanism in the contact area is that of abrasive polishing.

\section{Wear Rates}

Figure 12 displays the wear rates recorded when the samples were tested under the different contact loads. Testing showed all samples were able to withstand dry sliding contact with loads up to and including $20 \mathrm{~N}$, exhibiting a low $\mathrm{COF} \approx 0.25$ throughout all tests. The data clearly shows that the samples treated with $50 \%$ carbonates were 
the best performing, capable of producing a low wear rate for the duration of all the tests conducted.

Fig. 12

Wear rate of pack carburized titanium $\left(925^{\circ} \mathrm{C}, 20 \mathrm{~h}\right)$ produced under various loads and after using pack compositions of: 30,40 and $50 \%$

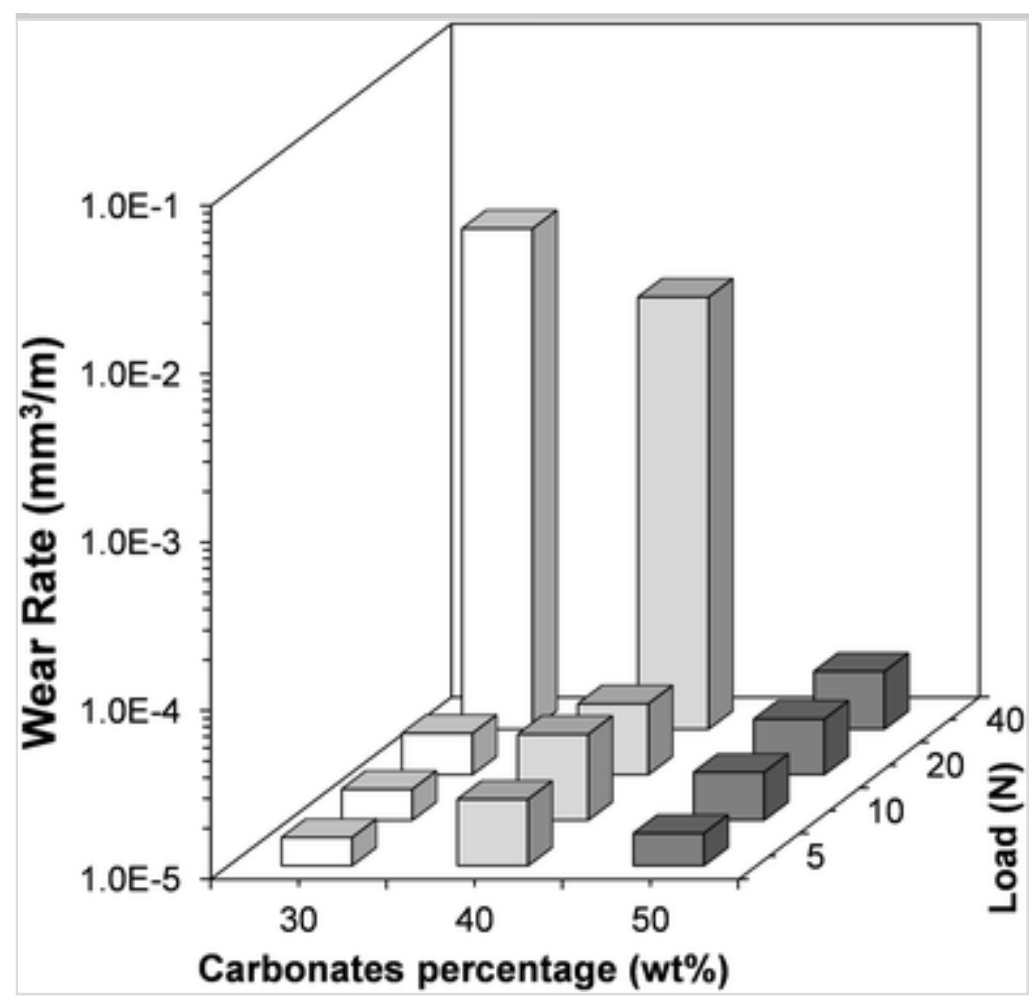

When considering the frictional response with regard to the depth of the TiC layer (Fig. 10), there is a clear correlation between low friction/wear and the thickness of the TiC network layer. The thicker the TiC network layer, the longer the sample is able to exhibit low friction and wear resistance. Therefore, it can be deduced that the extent of the TiC network layer is the determining factor in the generation of low friction and wear. When the wear rates for the treated titanium is compared with that of the untreated titanium (Fig. 7), a significate wear rate reduction is observed, irrespective of the carbonate percentage.

This study has demonstrated that the carbonate concentrations within the pack are directly linked to the thickness of the TiC network layer structure. This occurs as increasing the carbonate concentration ultimately increases the amount of $\mathrm{CO}$ available to react with the 
titanium substrate at any one time. Increasing the source concentration will result in increased carbon diffusion (Flick's 2nd law Ref 35).

When the titanium was treated at a temperature of $925^{\circ} \mathrm{C}$ for a duration of $20 \mathrm{~h}$, the optimal pack composition was that of: 6-part C, 3 part $\mathrm{BaCO}_{3}, 2$ part $\mathrm{Na}_{2} \mathrm{CO}_{3}$ and 1 part $\mathrm{CaCO}_{3}$. The resulting structure generates very low friction and wear. The low COF observed can be attributed to the TiC network structure. The optimized treatment also improved the load bearing capacity of the titanium, allowing the titanium to withstand a load of $40 \mathrm{~N}$ (surface contact pressure $\approx 1.5$ $\mathrm{GPa}$ ) in dry sliding conditions.

\section{Benefits of the PCOD Treatment}

The experimental results presented clearly demonstrate the importance of process conditions on the effectiveness of the PCOD treatment. When coupled with the optimal conditions, the tribological performance of CP-Ti is much improved and is able to produce low material loss rates and friction coefficients. This improved wear resistance observed using the PCOD treatment has been directly attributed to the presence of carbon within the titanium's subsurface structure. When high levels of carbon are present, a new subsurface network structure is generated; the presence of this carbon-rich network has significant tribological benefits, due to its high hardness. The network-like nature of this film means that there is no discernible interface and thus removes the delamination/spallation issue often associated with thermal oxidation (Ref 19). While high hardness is a desirable characteristic in wear reduction, the load bearing capacity of the subsurface is also of great importance. The PCOD treatment improves load bearing capacity by producing an extended oxygen diffusion zone. The effectiveness of this diffusion zone is demonstrated by treated samples ability to withstand a contact load of $40 \mathrm{~N}$.

From the test conditions investigated, we see that using a treatment temperature of $925^{\circ} \mathrm{C}$ and a pack composition of 1 part carbon to 1 part energizer, a surface coating is produced that was able to survive the wear test under a contact load of $40 \mathrm{~N}$. The optimal conditions can be attributed to the amount of $\mathrm{CO}$ produced by the breakdown of the 
carbonates within the pack, as such the more $\mathrm{CO}$ produced the greater the extent of carbon diffusion within the 20-h duration. It is anticipated that increasing the duration of the process will also increase the extent of carbon diffusion and the thus the size overall thickness of the network layer. The combination of network layer and ODZ has a profound effect on the wear mechanisms encountered by the treated titanium by changing the dominant mode from adhesion to abrasion

When investigating the wear mechanisms, we see the optimized PCOD increases the $\mathrm{H} / \mathrm{E}$ ratio and as such, the treatment wear mechanism is dominated by simple abrasive polishing; this is the stark contrast to the adhesive wear that dominates untreated titanium. The friction coefficients for the PCOD-Ti are also much improved over that associated with untreated titanium (as shown in Fig. 10) and ultimately lead to much improved rates of wear.

\section{Conclusions}

This study aimed to find the optimal process conditions for improving the tribological response of titanium using pack carburization with limited oxygen diffusion. The optimized process was able to generate in a multilayered structure comprising of a titanium carbide (TiC) network layer atop of a relatively thick $\alpha$-Ti(O) diffusion zone.

To determine the coating effectiveness, the TLMR was used as the key criterion. Using TMLR, various conclusions can be made regarding the optimal conditions for improving wear resistance:

1. The optimal temperature for the pack carburization of $\mathrm{CP}$-titanium with oxygen diffusion was that of $925^{\circ} \mathrm{C}$.

2. The optimal pack composition was that of 6 part $\mathrm{C}, 3$ part $\mathrm{BaCO}_{3}$, 2 part $\mathrm{Na}_{2} \mathrm{CO}_{3}$ and 1 part $\mathrm{CaCO}_{3}$.

Under dry sliding against an alumina counter face, the optimized treatment exhibited low and stable friction coefficients of $\mu \approx 0.2$. The wear was also shown to be at least two orders of magnitude lower than that of the untreated Ti. 


\section{Acknowledgments}

I (RB) would like to acknowledge the financial support of De Montfort University for providing a Ph.D. scholarship. Special thanks are also due to The Alderman Newton's Educational Foundation, The Sidney Perry Foundation, and The Wyvernian Foundation for providing additional financial support during the course of this work.

\section{References}

1. S. Kumar, T.S.N.S. Narayanan, S.G.S. Raman, and S.K. Seshadri, Fretting Corrosion Behaviour of Thermally Oxidized CP-Ti in Ringer's Solution, Corros Sci, 2010, 52, p 711-721

2. É. Martin, M. Azzi, G.A. Salishchev, and J. Szpunar, Influence of Microstructure and Texture on the Corrosion and Tribocorrosion Behavior of Ti-6Al-4V, Tribol Int, 2010, 43, p 918-924

3. D.G. Bansal, O.L. Eryilmaz, and P.J. Blau, Surface Engineering to Improve the Durability and Lubricity of Ti-6Al-4V Alloy, Wear, 2011, 271, p 2006-2015

4. A. Bloyce, Surface Engineering of Titanium Alloys for Wear Protection, Proc Inst Mech Eng J, 1998, 212, p 467-476

5. H. Dong and T. Bell, Enhanced Wear Resistance of Titanium Surfaces by a New Thermal Oxidation Treatment, Wear, 2000, 238, p 131-137

6. C. Lee, A. Sanders, N. Tikekar, and K.S.R. Chandran, Tribology of Titanium Boride-Coated Titanium Balls Against Alumina Ceramic: Wear, Friction, and Micromechanisms, Wear, 2008, 265, p 375-386

7. B. Sarma, N.M. Tikekar, and K.S.R. Chandran, Kinetics of Growth of Superhard Boride Layers During Solid State Diffusion of Boron into Titanium, Ceram Int, 2012, 38, p 6795-6805 
8. S. Barril, S. Mischler, and D. Landolt, Triboelectrochemical Investigation of the Friction and Wear Behaviour of TiN Coatings in a Neutral Solution, Tribol Int, 2001, 34, p 599-608

9. A. Zhecheva, W. Sha, S. Malinov, and A. Long, Enhancing the Microstructure and Properties of Titanium Alloys Through Nitriding and Other Surface Engineering Methods, Surf Coat Technol, 2005, 200, p 2192-2207

10. A. Ashrafizadeh and F. Ashrafizadeh, Structural Features and Corrosion Analysis of Thermally Oxidized Titanium, $J$ Alloy Compd, 2009, 480, p 849-852

11. R. Bailey and Y. Sun, Unlubricated Sliding Friction and Wear Characteristics of Thermally Oxidized Commercially Pure Titanium, Wear, 2013, 308, p 61-70

12. M. Jamesh, T.S.N.S. Narayanan, and P.K. Chu, Thermal Oxidation of Titanium: Evaluation of Corrosion Resistance as a Function of Cooling Rate, Mater Chem Phys, 2013, 138, p 565-572

13. P.A. Dearnley, K.L. Dahm, and H. Çimenoğlu, The CorrosionWear Behaviour of Thermally Oxidised CP-Ti and Ti-6Al-4V, Wear, 2004, 256, p 469-479

14. Y. Luo, H. Jiang, G. Cheng, and H. Liu, Effect of Carburization on the Mechanical Properties of Biomedical Grade Titanium Alloys, J Bionic Eng, 2011, 8, p 86-89

15. A. Haseeb, M.F. Islam, M.O. Alam and S. Tofail, Surface Hardening Behavior of Titanium Alloys in Carburization. Titan Extr Process, 1997, p 163-173

AQ1

16. N. Makuch, M. Kulka, P. Dziarski, and D. Przestacki, Laser Surface Alloying of Commercially Pure Titanium with Boron and Carbon, Opt Lasers Eng, 2014, 57, p 64-81 
17. L. Qin, C. Liu, K. Yang, and B. Tang, Characteristics and Wear Performance of Borided Ti6A14V Alloy Prepared by Double Glow Plasma Surface Alloying, Surf Coat Technol, 2013, 225, p 92-96

18. G. Kartal, S. Timur, M. Urgen, and A. Erdemir, Electrochemical Boriding of Titanium for Improved Mechanical Properties, Surf Coat Technol, 2010, 204, p 3935-3939

19. H. Dong and X.Y. Li, Oxygen Boost Diffusion for the DeepCase Hardening of Titanium Alloys, Mater Sci Eng A, 2000, 280, p $303-310$

20. R. Bailey and Y. Sun, Pack Carburisation of Commercially Pure Titanium with Limited Oxygen Diffusion for Improved Tribological Properties, Surf Coat Technol, 2015, 261, p 28-34

21. R.C. Sharma, Principles of Heat Treatment of Steels, New Age International, New Delhi, 2003

22. H. Dong, A. Bloyce, P.H. Morton, and T. Bell, Surface Engineering to Improve Tribological Performance of Ti-6Al-4V, Surf Eng, 1997, 13, p 402-406

23. E. Bucur and F.C. Wagner, Rate of Diffusion of Carbon in Alpha and in Beta Titanium as a Function of the Temperature and Concentration. Final technical report for period December 12, 1952July 1, 1954, Horizons, Inc. 1954

24. F. Borgioli, E. Galvanetto, F.P. Galliano, and T. Bacci, Air Treatment of Pure Titanium by Furnace and Glow-Discharge Processes, Surf Coat Technol, 2001, 141, p 103-107

25. R. Bailey and Y. Sun, Corrosion and Tribocorrosion Performance of Pack-Carburized Commercially Pure Titanium with Limited Oxygen Diffusion in a $0.9 \% \mathrm{NaCl}$ Solution, J Bio- TriboCorros, 2018, 4, p 6 
26. L. Meier, N. Schaal, and K. Wegener, In-Process Measurement of the Coefficient of Friction on Titanium, Proc CIRP, 2017, 58, p $163-168$

27. I. Arvanitidis, D. Siche, and S. Seetharaman, A Study of the Thermal Decomposition of $\mathrm{BaCO}_{3}$, Metall Mater Trans B, 1996, 27, p 409-416

28. A.K. Galwey and M.E. Brown, Thermal Decomposition of Ionic Solids: Chemical Properties and Reactivities of Ionic Crystalline Phases, Elsevier Science, Amsterdam, 1999

29. J. Kim and H. Lee, Thermal and Carbothermic Decomposition of $\mathrm{Na}_{2} \mathrm{CO}_{3}$ and $\mathrm{Li}_{2} \mathrm{CO}_{3}$, Metall Mater Trans $B, 2001,32$, p 17-24

30. B.V. L'vov, Thermal Decomposition of Solids and Melts: New Thermochemical Approach to the Mechanism, Kinetics and Methodology, Springer, Dordrecht, 2007

31. S. Kumar, T.S.N.S. Narayanan, S.G.S. Raman, and S.K. Seshadri, Evaluation of Fretting Corrosion Behaviour of CP-Ti for Orthopaedic Implant Applications, Tribol Int, 2010, 43, p 1245-1252

32. A.R. Shankar, N.S. Karthiselva, and U.K. Mudali, Thermal Oxidation of Titanium to Improve Corrosion Resistance in Boiling Nitric Acid Medium, Surf Coat Technol, 2013, 235, p 45-53

33. A. Maitre, D. Tetard, and P. Lefort, Role of some Technological Parameters During Carburizing Titanium Dioxide, J Eur Ceram Soc, 2000, 20, p 15-22

34. R.J. Van Thyne, E.S. Bumps, H.D. Kessler, and M. Hansen, Phase Diagrams of the Titanium-Aluminum, Titanium-ChromiumIron, and Titanium-Oxygen Alloy Systems, WADC Tech Rep, 1952, 52-16, p 96

35. L.H. VanVlack, Materials Science for Engineers, World Student Series edn., Addison-Wesley, Reading, Mass, 1974 
